\title{
Urogenital Chlamydia trachomatis in the environment of soldiers from the Polish Special Forces
}

\author{
Krzysztof Korzeniewski ${ }^{1, A-F}$ \\ ${ }^{1}$ Department of Epidemiology and Tropical Medicine, Military Institute of Medicine, Warsaw, Poland \\ A - Research concept and design, B - Collection and/or assembly of data, C - Data analysis and interpretation, \\ $D$ - Writing the article, E-Critical revision of the article, F-Final approval of article
}

Korzeniewski K. Urogenital Chlamydia trachomatis in the environment of soldiers from the Polish Special Forces. Ann Agric Environ Med. 2019; 26(1): 51-54. doi: 10.26444/aaem/85591

\begin{abstract}
Introduction and objective. Urogenital Chlamydia trachomatis is one of the most common sexually transmitted bacterial pathogens. The aim of the study was to present the current occurrence of chlamydial infections among Polish soldiers, sexually-active men and women at reproductive age.

Materials and method. The research involved 253 active duty soldiers from the Polish Special Forces, 237 men and 16 women aged 26-57, stationed in Warsaw between October - November 2016. The study participants were asked to fill a socio-demographic questionnaire and then subjected to diagnostic tests. These included a urine test for the presence of Chlamydia trachomatis DNA using the Real-Time PCR assay with fluorescently labeled markers and probes, complementary to plasmid DNA of the bacteria (DNA isolated from urine samples was used as matrix).

Results. Chlamydia trachomatis infection was detected in two male soldiers, non-commissioned officers, at mean age 40.5 years (total: 38.0 years); reporting sexual contacts with 2-3 partners in the last 12 months (total: 141 soldiers - 1 partner, 66 - 2-3 partners, 46 - >4 partners), with no UTI symptoms.

Conclusions. Among all the study participants, of whom more than $40 \%$ reported sexual contacts with 2-4 or more partners within the last 12 months, only $0.8 \%$ were found to be infected. The low prevalence of Chlamydia trachomatis infection can be associated with a regular or frequent use of STI prevention measures during casual sex, or having a single sexual partner.
\end{abstract}

\section{Key words}

RT-PCR, Chlamydia trachomatis, Polish soldiers

\section{INTRODUCTION}

Urogenital Chlamydia trachomatis is an intracellular gramnegative bacteria transmitted by oral, vaginal or anal sex; it can also be transmitted vertically, from a mother to her newborn child during a vaginal delivery [1]. The risk of transmission from a single episode of sexual intercourse is estimated to be $10-20 \%[2,3]$. The most common risk factors for Ch. trachomatis infections are risky sexual behaviours (sex with prostitutes, casual sex with strangers, sex with multiple partners, homosexuality, sex with partners taking drug injections, sex with partners likely to have sexuallytransmitted infections /STI's/ carriers, unprotected sex /condoms/) [4]. The infection is asymptomatic in nearly $90 \%$ of infected men and $70 \%$ of women [5].

The significant problem associated with Ch. trachomatis infection is its long incubation period and its frequent transition into a chronic form which may persist for many years. Transmitting the infection to other sexual partners can lead to delayed complications, including epididymitis, orchitis in men, and ectopic pregnancy and infertility in women [6]. Signs and symptoms of the infection in women include cervicitis (mucopurulent endocervical discharge, easily induced endocervical bleeding), sometimes urethritis (pyuria, dysuria, urinary frequency). The infection can spread

Address for correspondence: Krzysztof Korzeniewski, Military Institute of Medicine, Department of Epidemiology and Tropical Medicine, Szaserów St. 128 04-141 Warszawa, Poland

e-mail: kkorzeniewski@wim.mil.pl

Received: 18.11.2017; accepted: 21.02.2018; first published: 23.03.2018 from the cervix to the upper reproductive tract (uterus, fallopian tubes) causing pelvic inflammatory disease [7]. Signs and symptoms in men include burning, frequent and painful urination, penile discharge, swollen and painful testicles [8].

Chlamydia trachomatis is a cosmopolitan infection with a global incidence estimated at 61.1 million cases in 2015 [9]. According to the World Health Organization (WHO) more than $50 \%$ of new cases are reported in South and South East Asia [4]. In the European Union, approx. 400,000 cases are diagnosed every year [5]. Chlamydia infection is the most common bacterial sexually-transmitted infection (STI) in the United States $(1,526,658$ cases were reported to the Centers for Disease Control and Prevention, and an estimated 2.86 million infections occur annually) [10]. A large number of cases are not reported because most people with $C h$. trachomatis are asymptomatic and do not seek testing or medical assistance. The global prevalence of Chlamydia infections among women/men aged 15-49 years is estimated at $4.2 \%$ and $2.7 \%$, respectively [11]. Twothirds of the infections occur in people aged 15-24 [12]. Women are more often screened for Chlamydia than men, which is associated with the fact that they receive regular gynaecological and prenatal care, and they are more likely to develop a symptomatic urogenital infection [13]. The biological material used for $\mathrm{Ch}$. trachomatis tests in adults is usually a cervical or a vaginal swab, and a urine sample in women, and a urethral swab or urine sample in men. The number of patients giving consent for Chlamydia screening tests, as well as the number of tests performed, largely 
increased when molecular diagnostics were introduced. Molecular biology testing, based on nucleic acid amplification tests (in particular non-invasive urine examination in men), have largely replaced culture or enzyme immunoassays owing to its high sensitivity [14]. In general, chlamydial infections are more often found among sexually-active individuals with multiple sexual partners. They are presently considered one of the most significant public health issues globally, also in the military environment [15].

The aim of the study was to present the current occurrence of Chlamydia trachomatis infections among the Polish Special Forces soldiers, sexually-active men and women at reproductive age.

\section{MATERIALS AND METHOD}

Ethics. The research project entitled "Prevalence of selected infections in the environment of soldiers from the Special Forces" was accepted by the Committee on Bioethics at the Military Institute of Medicine (Decision No 41/2016, dated 15 July 2016) on the basis of the Declaration of Helsinki (2013) and the rules elaborated by the European Union, "Good clinical practice for trials on medicinal products in the European Community. The rules governing medicinal products in the European Community" (1990), ratified by the Ethics Committee in Poland (March 1993).

Study population. The research involved 253 active duty soldiers from the Polish Special Forces stationed in Warsaw between October - November 2016; 237 men and 16 women aged 26-57. The study participants were asked to fill-in a socio-demographic questionnaire and then subjected to diagnostic tests. These included a urine test for the presence of Chlamydia trachomatis DNA using the Real-Time Polymerase Chain Reaction (PCR) assay with fluorescently labeled markers and probes, complementary to plasmid DNA of the bacteria (DNA isolated from urine samples was used as matrix). The tests were carried out using the Abbott m2000rt assay.

The following exclusion criteria were applied: patients using antibiotics or other antimicrobial agents (p.o./i.v./i.m.) within 7 days before the test; patients using vaginal preparations or medications applied to external genitals within 48 hours before the test; female patients during menstruation.

Preparation of patients and samples. Patients had to avoid sexual activity and limit their genital hygiene 24 hours before the test; patients collected $20-30 \mathrm{ml}$ of first catch urine into a sterile container (they must not have urinated during the previous hour); the urine sample was delivered to a test site within 2 hours after sample collection. Up to 3 hours after collection, each urine sample (approx. $3 \mathrm{ml}$ ) was transferred to a tube containing a liquid transport medium (guanidine thiocyanate in Tris buffer) Abbott multi-Collect Specimen Collection Kit (Abbott, Germany). Up to 24 hours after collection, each urine sample was examined qualitatively by Real Time PCR assay.

Laboratory procedures. Real-Time PCR assays with fluorescently labeled markers and probes specific for plasmid DNA of Chlamydia trachomatis were used:
- sample preparation - a urine sample containing epithelial cells was treated with a detergent solution to release Chlamydia trachomatis DNA contained in the chlamydial reticulate bodies; a second detergent solution was then added to prepare the lysed specimen for amplification;

- PCR amplification - selection and amplification of the target sequence, internal control amplification, selective amplification;

- PCR product detection - the use of dual fluorescent dyelabeled probes allows for the real time detection of the PCR products by measuring the fluorescence intensity from the reporter dyes released during the amplification process. Probes consisted of oligonucleotides specific for Chlamydia trachomatis (CT) cryptic plasmid DNA, the CT ompA gene and the CT internal control, labeled with reporter and quencher dyes.

During the PCR reaction the probes are hybridized to the target sequence and then cleaved by 5 ' and 3' nuclease activity of the thermostable Z05 DNA polymerase; the amplification of the CT cryptic plasmid DNA and/or the target ompA gene DNA were measured independently and at a different wavelength than the CT internal control. The process was repeated for a specified number of cycles, each time with an effectively increased fluorescent intensity of the reporter dyes, permitting independent identification of the Chlamydia trachomatis DNA and the CT internal control.

Statistical analysis. Statistical analysis was performed using the statistical programme StatSoft. Inc. (2011), Statistica (data analysis software system), version 10.0. (SN JGNP3087539302AR-E), and Excel. The quantitive variables were characterized by the arithmetic mean of standard deviation or median or $\mathrm{max} / \mathrm{min}$ (range). Statistical significance of differences between 2 groups (unpaired variables model) was processed with the t-Student test (or Welch test in the case of lack of homogeneity), or U MannWithney test (in cases where conditions of performing the t-Student test were not satisfied or for variables measured by ordinal scale). Chi-squared tests for independence were used for qualitative variables. The qualitative variables were presented with the use of count and percentage. In all the calculations, the level of significance $\mathrm{p}=0.05$ was used.

\section{RESULTS}

Chlamydia trachomatis infection was detected in 2 male soldiers, non-commissioned officers, at mean age 40.5 years, reporting sexual contacts with 2-3 partners in the last 12 months, using condoms in $50 \%$, with no urinary tract infection (UTI) symptoms (Tab. 1).

There was no statistically significant difference regarding the age of the soldiers and the Chlamydia trachomatis infection distribution $(\mathrm{p}=0.4594)$. It was not possible to calculate the statistical significance of age between infected and non-infected patients, due to the small number of the infected individuals $(n=2)$. There were no statistically significant differences between the marital status of soldiers examined ( $\mathrm{p}=0.7307)$, the number of sexual partners in the last 12 months $(p=0.3247)$, the use of condoms $(p=0.8762)$ or the presence of symptoms $(\mathrm{p}=0.9986)$ and the presence of Chlamydia trachomatis infection. 
Table 1. Sociodemographic variables of soldiers tested for Chlamydia trachomatis infection using RT-PCR $(n=253)$

\begin{tabular}{|c|c|c|c|}
\hline Socio-demographic variables & $\begin{array}{l}\text { Infected with } \\
\text { Chlamydia } \\
\text { trachomatis } \\
(\mathrm{n}=2)\end{array}$ & $\begin{array}{l}\text { Non-infected } \\
\text { with Chlamydia } \\
\text { trachomatis } \\
(\mathrm{n}=251)\end{array}$ & $P$-value \\
\hline \multicolumn{3}{|l|}{ Age } & \multirow{3}{*}{---} \\
\hline Mean (SD) & $40.5(0.7)$ & $38.0(5.5)$ & \\
\hline Range & $40.0-41.0$ & $26.0-57.0$ & \\
\hline \multicolumn{3}{|l|}{ Sex } & \multirow{3}{*}{0.2760} \\
\hline Women & $0(0.0 \%)$ & $16(6.4 \%)$ & \\
\hline Men & $2(100.0 \%)$ & $235(93.6 \%)$ & \\
\hline \multicolumn{3}{|l|}{ Military rank } & \multirow{3}{*}{0.9325} \\
\hline Officer & $0(0.0 \%)$ & $70(27.9 \%)$ & \\
\hline Non-commissioned officer & $2(100.0 \%)$ & $181(72.1 \%)$ & \\
\hline \multicolumn{3}{|l|}{ Marital status } & \multirow{4}{*}{0.7307} \\
\hline Single & $1(50.0 \%)$ & $64(25.5 \%)$ & \\
\hline Married & $1(50.0 \%)$ & $186(74.1 \%)$ & \\
\hline Partnership & $0(0.0 \%)$ & $1(0.4 \%)$ & \\
\hline \multicolumn{3}{|l|}{$\begin{array}{l}\text { Number of sexual partners in the } \\
\text { last } 12 \text { months }\end{array}$} & \multirow{4}{*}{0.3247} \\
\hline 1 & $0(0.0 \%)$ & $141(56.2 \%)$ & \\
\hline $2-3$ & $2(100.0 \%)$ & $64(25.5 \%)$ & \\
\hline$>4$ & $0(0.0 \%)$ & $46(18.3 \%)$ & \\
\hline \multicolumn{3}{|l|}{ Use of condoms } & \multirow{5}{*}{0.8762} \\
\hline Yes, regularly & $1(50.0 \%)$ & $105(41.8 \%)$ & \\
\hline No & $0(0.0 \%)$ & $85(33.9 \%)$ & \\
\hline Sometimes & $1(50.0 \%)$ & $50(19.9 \%)$ & \\
\hline Often & $0(0.0 \%)$ & $11(4.4 \%)$ & \\
\hline \multicolumn{3}{|l|}{ Presence of symptoms } & \multirow{6}{*}{0.9986} \\
\hline No symptoms & $2(100.0 \%)$ & $238(94.8 \%)$ & \\
\hline Urethral discharge, burning & $0(0.0 \%)$ & $1(0.4 \%)$ & \\
\hline Frequent urination & $0(0.0 \%)$ & $2(0.8 \%)$ & \\
\hline Urethral burning & $0(0.0 \%)$ & $8(3.2 \%)$ & \\
\hline Urinary urgency & $0(0.0 \%)$ & $2(0.8 \%)$ & \\
\hline \multicolumn{3}{|c|}{ History of Ch. trachomatis infection } & \multirow{3}{*}{---} \\
\hline Yes & $0(0.0 \%)$ & $0(0.0 \%)$ & \\
\hline No & $2(100.0 \%)$ & $251(100.0 \%)$ & \\
\hline \multicolumn{3}{|l|}{ History of other STIs } & \multirow{3}{*}{---} \\
\hline Yes & $0(0.0 \%)$ & $0(0.0 \%)$ & \\
\hline No & $2(100.0 \%)$ & $251(100.0 \%)$ & \\
\hline \multicolumn{3}{|l|}{ Receiving STI treatment } & \multirow{3}{*}{---} \\
\hline Yes & $0(0.0 \%)$ & $0(0.0 \%)$ & \\
\hline No & $2(100.0 \%)$ & $251(100.0 \%)$ & \\
\hline \multicolumn{3}{|c|}{$\begin{array}{l}\text { Use of antimicrobial agents within } \\
\text { the last } 7 \text { days }\end{array}$} & \multirow{3}{*}{. } \\
\hline Yes & $0(0.0 \%)$ & $0(0.0 \%)$ & \\
\hline No & $2(100.0 \%)$ & $251(100.0 \%)$ & \\
\hline
\end{tabular}

\section{DISCUSSION}

This research presents the results of a study into the prevalence of Chlamydia trachomatis infections in the group of soldiers from the Polish Special Forces. The study participants were all sexually-active men and women, of whom $43.8 \%$ reported sexual contacts with $2-4$ or more partners in the last 12 months. $41.9 \%$ reported the regular use of condoms during sexual intercourse and $57.3 \%$ had a single sexual partner, which could potentially be the cause of the very low infection rates. The military environment has always been of special interest to the medical services with regard to the spread of infections and the routes of disease transmission, including sexual transmission. The military environment is an example of a closed community with professional activities very different from those experienced in the civilian environment. The soldiers are usually young, active and healthy men, frequently relocated to different military units across Poland or abroad, and reporting sexual contacts with both steady and casual sex partners. Chlamydia tests are routinely performed in military personnel, and especially among soldiers from the US Forces. Chlamydia infection has been the most commonly reported STD in the US Forces for many years [16]. Still in the early 1990 s, the prevalence rate of $C h$. trachomatis infections among the US soldiers was as high as $15.6 \%$, especially among young recruits $[17,18]$. A research study conducted several years later, between 2005-2010, involving 67,425 US Forces soldiers stationed in Fort Bragg (North Carolina, USA), one of the largest military bases in the USA, showed the overall prevalence of Chlamydia trachomatis infections of $3.3 \%$ in the study group $(n=2,198)$. Such a drastic reduction in Chlamydia cases might have been attributable to a more regular use of STI prevention measures (condoms), mostly resulting from the fear of the global AIDS epidemic. Chlamydiasis was more often found in female soldiers, under 26 years of age, with lower rank, single, of non-white race [19]. American soldiers are a high-risk group as far as the incidence of STD's is concerned, as much as $40 \%$ of the US military personnel are under 25 years of age. Also, for this reason, the medical authorities of the US Army recommended screening for $C h$. trachomatis in all young recruits joining the United States Armed Forces [20].

Screening tests for chlamydial infections are very rarely performed in soldiers from the Polish Armed Forces; therefore, the actual prevalence rates of Chlamydia trachomatis in the military environment in Poland is unknown; to-date, only 2 such studies have been conducted. Apart from the research project discussed in the presented article, Korzeniewski et al. conducted a similar study between March - April 2012. The study involved 66 professional soldiers, healthy, asymptomatic men, aged $27-44$, serving in a military unit in Warsaw. Urine samples taken from patients were investigated using molecular methods (Cobas TaqMan, RT-PCR). Of all the study participants, 2 soldiers were found to be infected (aged 33 and 34-years-old) with Ch. trachomatis (3.0\%). They both reported casual sex without STI prevention measures with $>4$ women in the last 12 months. In contrast, twothirds of the examined group of soldiers reported the use of condoms during casual sexual contacts. According to the examined men, the regular use of STI prevention measures was associated with the fear of HIV infection [21].

The National Institute of Public Health - National Institute of Hygiene is the main governmental body responsible for monitoring the incidence rates of infectious diseases in Poland. Its first report on Chlamydia trachomatis prevalence in the general Polish population was issued in 2013. Between January - December 2013, sanitary and epidemiological stations and other medical facilities reported 309 Chlamydia cases across Poland (incidence 0.8/100,000 residents). The 
report of 2016 showed 232 Ch. trachomatis infections (incidence 0.6/100,000 residents) [22]. It is difficult to assess whether such prevalence of chlamydial infections in a 38-million population is due to low detection rates (accidental diagnosis of symptomatic cases) or if it proves low incidence of chlamydial infections in the Polish population. All the previous studies carried out among professional soldiers, who are generally at a greater risk for an STI infection than other occupational groups, demonstrated low prevalence rates of Chlamydia infections, especially in the USA and the EU countries.

Limitations. The research task involved only those soldiers who gave informed consent to participate in the study, which limited the number of participants and the number of tests performed. The study group represented over $50 \%$ of the total manpower of the pre-selected military unit, and over $10 \%$ of the Polish Special Forces manpower.

\section{CONCLUSIONS}

Among all the study participants, of whom more than $40 \%$ reported sexual contacts with 2-4 or more partners within the last 12 months, only $0.8 \%$ were found to be infected. The low prevalence of Chlamydia trachomatis infection can be associated with the regular or frequent use of STI prevention measures during casual sex, or having a single sexual partner.

\section{Conflict of interests}

The author declares no conflicts of interests in relation to this article.

\section{Acknowledgements}

The study was supported by the Polish Ministry of Science and Higher Education (Subject No 391/2016, entitled "Assessment of prevalence of sexually transmitted Chlamydia trachomatis infections in the military environment", Military Institute of Medicine in Warsaw, Poland). The author is grateful to the medical team from military unit No. 2305 in Warsaw for their excellent technical assistance and supervision in patient recruitment and collection of biological samples.

\section{REFERENCES}

1. Centers for Disease Control and Prevention. Sexually Transmitted Diseases Treatment Guidelines, 2010. MMWR 2010; 59: 1-116.

2. Cates W, Steiner M. Dual protection against unintended pregnancy and sexually transmitted infections: what is the best contraceptive approach? Sex Transm Dis 2002; 293: 168-74. https://doi.org/10.1097/00007435200203000-00007.

3. Althaus C, Heijne J, Low N. Towards more robust estimates of the transmissibility of Chlamydia trachomatis. Sex Trans Dis 2012; 39: 402-4. https://doi.org/10.1097/OLQ. 0b013e318248a550.

4. World Health Organization. Sexually transmitted infections (STIs), fact sheet No 110. Geneva: WHO; 2015.
5. Global Infectious Diseases and Epidemiology Network. Chlamydia Infections, Worldwide. Available at: https://web.gideonline.com/web/ epidemiology. Access: 29 Aug 2017.

6. Ahmadi MH, Mirsalehian A, Bahador A. Association of Chlamydia trachomatis with infertility and clinical manifestations: a systematic review and meta-analysis of case-control studies. Infect Dis. (Lond) 2016; 48(7): 517-23. https://doi.org/10.3109/ 23744235. 2016.1160421.

7. Haggerty CL, Gottlieb SL, Taylor BD, Low N, Xu F, Ness RB. Risk of sequelae after Chlamydia trachomatis genital infection in women. J Infect Dis 2010; 201(Suppl2): S134-55. https://doi.org/10.1086/652395.

8. Cunningham KA, Beagley KW. Male genital tract chlamydial infection: implications for pathology and infertility. Biol Reprod. 2008; 79: 180-9. https://doi.org/10.1095/ biolreprod. 108.067835.

9. Vos T, Allen C, Arora M, Barber RM, Bhutta ZA, Brown A, et al. Global, regional, and national incidence, prevalence, and years lived with disability for 310 diseases and injuries, 1990-2015. Lancet 2016; 388(10053): 1545-1602. https://doi.org/10.1016/ S0140-6736(16)31678-6.

10. Centers for Disease Control and Prevention. Sexually Transmitted Disease Surveillance, 2015. Atlanta, GA: Department of Health and Human Services; October 2016.

11. Newman L, Rowley J, Vander Hoorn S, Wijesooriya NS, Unemo M, Low N, et al. Global Estimates of the Prevalence and Incidence of Four Curable Sexually Transmitted Infections in 2012 Based on Systematic Review and Global Reporting. PLoS One 2015; 10(12): e0143304. https:// doi.org/10.1371/journal.pone.0143304.

12. Satterwhite CL, Torrone E, Meites E, Dunne EF, Mahajan R, Ocfemia $\mathrm{MC}$, et al. Sexually transmitted infections among US women and men: prevalence and incidence estimates, 2008. Sex Transm Dis. 2013; 40(30): 187-93. https://doi.org/10.1097/ OLQ.0b013e318286 bb53.

13. Dielissen PW, Teunissen DA, Lagro-Janssen AL. Chlamydia prevalence in the general population: is there a sex difference? a systematic review. BMC Infect Dis. 2013; 13: 534. https://doi.org/10.1186/1471-2334-13534.

14. Association of Public Health Laboratories. Laboratory Diagnostic Testing for Chlamydia trachomatis and Neisseria gonorrhoeae. Expert Consultation Meeting Summary Report. January 13-15, 2009. Atlanta, GA.

15. Cook RL, Hutchison SL, Ostergaard L, Braithwaite RS, Ness RB. Systematic review: noninvasive testing for Chlamydia trachomatis and Neisseria gonorrhoeae. Ann Intern Med. 2005; 142: 914-25. https:// doi.org/10.7326/0003-4819-142-11-200506070-00010.

16. Lee SE, Nauschuetz W, Jordan N, Lindler L, Steece R, Pfau E, et al. Survey of sexually transmitted disease laboratory methods in US Army laboratories. Sex Transm Dis. 2010; 37(1): 44-8. doi.org/10.1097/ OLQ.0b013e3181b66dd6.

17. Berg SW. Sexually Transmitted Diseases and Human Immunodeficiency Virus Infection. In: Kelley PW (Ed.). Military Preventive Medicine: Mobilization and Deployment. Borden Institute Walter Reed Army Medical Center, Office of the Surgeon General at TMM Publications. Vol. 2. Washington DC, USA 2005, pp. 1146-75.

18. Cecil JA, Howell MR, Tawes JJ, Gaydos JC, McKee KT, Quinn TC, et al. Features of Chlamydia trachomatis and Neisseria gonorrhoeae infection in male Army recruits. J Infect Dis. 2001; 184(9): 1216-19. doi.org/10.1086/323662.

19. Hakre S, Oyler RJ, Ferrell KA, Li F, Michael NL, Scott PT, et al. Chlamydia trachomatis infection rates a cohort of mobile soldiers stationed at Fort Bragg, North Carolina, 2005-2010. BMC Public Health 2014; 14: 181. https://doi.org/10.1186/ 1471-2458-14-181.

20. Armed Forces Health Surveillance Center. Defense Medical Epidemiology Database. Available from: http://www.afhsc.mil. Accessed: 30 Aug 2017.

21. Korzeniewski K, Konior M, Lass A, Guzek A. Occurrence of Chlamydia trachomatis in military environment on the example of professional soldiers in the Polish Armed Forces. In Marit Health. 2014; 65(3): 137-41. doi.org/10.5603/IMH.2014.0028.

22. National Institute of Public Health - National Institute of Hygiene. Infectious diseases and poisonings in Poland in 2016. Available at: http://www.pzh.gov.pl/oldpage/ epimeld/2016/index_mp.html. Access: 30 Aug 2017 [in Polish]. 